\title{
Meta-analysis of nonsteroidal anti-inflammatory drug intake and prostate cancer risk
}

\author{
Xiao Wang, Yi-wei Lin, Jian Wu, Yi Zhu, Xiang-lai Xu, Xin Xu, Zhen Liang, Zheng-hui Hu, Shi-qi Li, \\ Xiang-yi Zheng and Li-ping Xie*
}

\begin{abstract}
Background: Epidemiological studies of the association between nonsteroidal anti-inflammatory drug (NSAID) intake and the risk of prostate cancer still remain controversial. Therefore, we conducted a meta-analysis to evaluate the potential association between NSAID intake and prostate cancer risk.

Methods: Eligible studies were retrieved by both computerized searches and reviews of references. Subgroup analyses on country and design of study were also performed. Random or fixed-effect models were used to pool estimates of odds ratios (ORs) with 95\% confidence intervals (Cls).

Results: We observed that the intake of aspirin was associated with a marginally decreased risk of prostate cancer $(\mathrm{OR}=0.95,95 \% \mathrm{Cl}=0.93$ to 0.98). A similar result was found between nonaspirin NSAIDs and prostate cancer risk $(\mathrm{OR}=0.94,95 \% \mathrm{Cl}=0.90$ to 0.98$)$. However, a positive relation between all-NSAID intake and prostate cancer risk was observed ( $\mathrm{OR}=1.18,95 \% \mathrm{Cl}=1.15$ to 1.22 ).

Conclusions: We observed a marginally inverse correlation between the intake of aspirin and prostate cancer risk. On the contrary, a positive relationship between all-NSAID intake and prostate cancer was detected. Further research needs to be conducted to better clarify potential biological mechanisms.
\end{abstract}

Keywords: Etiology, Meta-analysis, NSAIDs, Prostate cancer

\section{Background}

Prostate cancer is generally accepted as the most common type of cancer among men and ranks as the second cause of cancer-specific death in the whole world [1]. In the USA, approximately 238,590 men were diagnosed with prostate cancer, of which $12 \%$ were expected to die in 2013 [1]. Epidemiologic studies illustrated that both environmental and genetic alterations are well-established risk factors of prostate cancer [2,3]. However, this could hardly explain the different incidences of prostate cancer in different countries $[1,4]$. Therefore, daily lifestyle could play an important role in carcinogenesis.

Previous research demonstrated that nonsteroidal anti-inflammatory drugs (NSAIDs) could reduce the risk of several types of cancer, including colorectal cancer, esophageal cancer, and breast cancer [5-7]. Laboratory

\footnotetext{
*Correspondence: xielp@zjuem.zju.edu.cn

Department of Urology, The First Affiliated Hospital, School of Medicine,

Zhejiang University, 79 Qingchun Road, Hangzhou 310003, Zhejiang

Province, People's Republic of China
}

\section{Ciomed Central}

research has consistently illustrated that inflammation plays an essential role in prostate carcinogenesis [8]. It is generally accepted that cyclooxygenase enzymes, which are the targets of most NSAIDs, are involved in prostate carcinogenesis. A previous review, focusing on the potential relationship between NSAID intake and prostate cancer risk, showed that NSAIDs could prevent prostate cancer from developing into advanced disease, suggesting that NSAIDs could have a potentially protective effect on prostate cancer [9].

Nevertheless, epidemiological studies of the association between NSAID intake and the risk of prostate cancer still remained controversial. A previous meta-analysis in 2010 (including articles published before 2008) indicated that aspirin and other types of NSAID had a marginally, but not conclusively, protective effect on prostate cancer [10]. In addition, multicenter and large-sample studies were performed in the last 5 years, which provided us with more reliable statistics. 
Therefore, we conducted a meta-analysis to evaluate both the strength and consistency of the potential association between NSAID intake and prostate cancer risk. Stratified analyses were also conducted on possible variables.

\section{Methods}

\section{Literature search}

To obtain an overall view of NSAID intake and prostate cancer risk, we performed a comprehensive and systematic searching strategy. We searched for publications updated to October 2013 using PubMed, the Web of Science, and Cochrane Library. We selected the keyword search "“Anti-Inflammatory Agents, Non-Steroidal” [Mesh] OR "Aspirin" [Mesh]) AND "Prostatic Neoplasms" [Mesh]' to identify publications. Additional publications were assessed either by cited references in the recruited articles or reported meta-analyses on NSAID intake and prostate cancer risk. Each retrieved publication was evaluated for the following criteria: (1) case-control or cohort study assessing the potential correlation between NSAIDs intake and prostate cancer risk; (2) exact data in both case and control groups should be identified; (3) articles published before October 2013 written in English; (4) results including odds ratios (ORs) or relative risk and 95\% confidence intervals ( $95 \% \mathrm{CIs})$, or supplying sufficient information to calculate them. Studies with insufficient or overlapping data were excluded. Figure 1 illustrates the process of determining and selecting articles.

\section{Data extraction}

Data extracted from the articles included the name of the first author, year of publication, study period, country, type of NSAID, design of study, information resource, and odds ratio comparing the highest level of NSAID intake with the lowest. Given that prostate cancer is a relatively rare disease, the relative risk was considered to be the same as the OR. Therefore, we chose OR as the result to assess the potential relationship between NSAID intake and prostate cancer risk. Investigators were divided into two groups, and extracted data from all the potentially qualifying publications simultaneously, to avoid omissions or mistakes. Discussions were conducted whenever necessary.

\section{Statistical analysis}

A fixed-effects model using the method of Mantel and Haenszel [11] was selected to provide pooled estimation of the correlation between NSAID intake and prostate cancer risk when no heterogeneity was detected; otherwise, the random-effect model of the method of DerSiomonian and Laird [12] was selected for summarization.

We chose OR and 95\% CI to evaluate the strength of the relationship between NSAID intake (all NSAIDs, aspirin, and nonaspirin NSAIDs, respectively) and prostate cancer risk (prostate cancer and advanced prostate cancer, respectively). Advanced prostate cancer was defined as Gleason score $\geq 8$, clinical stage $\geq T_{2} C$, or prostate-specific antigen $\geq 10 \mathrm{ng} / \mathrm{ml}$. Stratified analyses were conducted by country (USA or other countries) and study design (cohort study or case-control).

We used the quantified $Q$ test [12] and $I^{2}$ test [13] to assess the extent of heterogeneity across eligible studies. Publication bias was evaluated by Egger's [14] and Begg's $[15]$ tests. The statistical significance level was set at 0.05 .

Sensitivity analyses were also conducted to evaluate the effect of each study on the overall estimate.

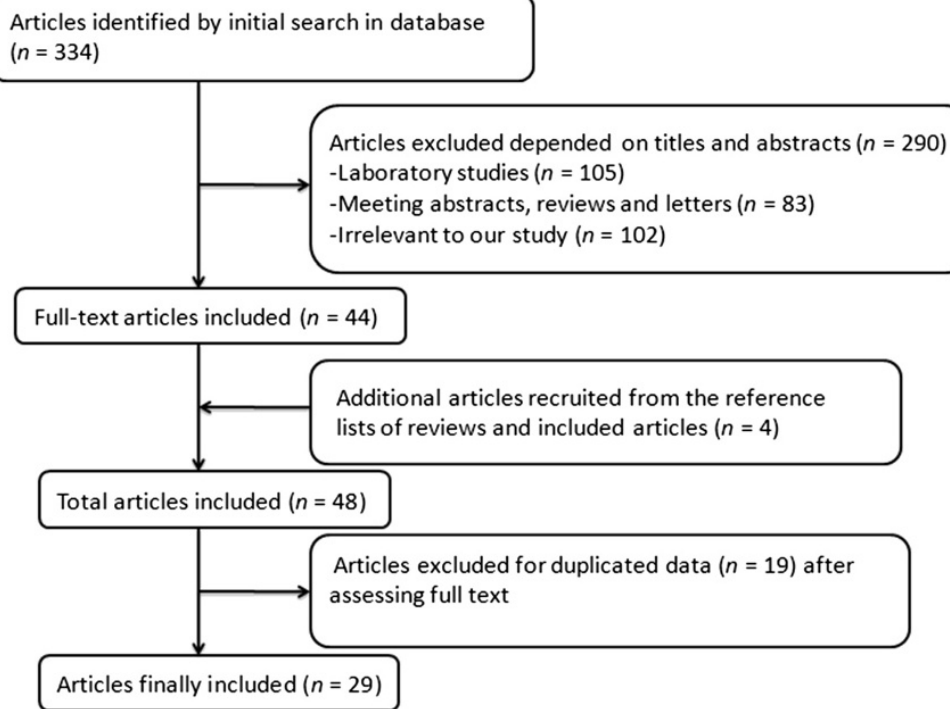

Figure 1 Article selection. 
All statistical analyses were conducted using STATA version 11 (StataCorp, College Station, Texas, USA).

\section{Results}

\section{Description of the meta-analysis}

A total of 334 articles were found when the mentioned keywords were used. After a closer examination, 309 articles were excluded based on titles and abstracts, while 4 articles were recruited from the reference lists of reviews and included articles [16-19]. Figure 1 illustrates the detailed process of identifying and selecting articles. Finally, we identified a total of 29 articles on NSAID intake and prostate cancer risk that were published between 1989 and 2013 [16-44].

Among the included articles, 15 were cohort studies $[16-20,22,24,28-30,33,36,37,39,40]$, and 14 were casecontrol ones [21,23,25-27,31,32,34,35,38,41-44]. Sixteen studies were conducted in the USA [16-18,20,22,24,25,28, $30,31,37,39-43]$, while the remaining 13 were performed in other countries $[19,21,23,26,27,29,32-36,38,44]$. Eleven studies were associated with all-NSAID intake [19,20,26-28, $32-34,38,42,44]$, 24 with aspirin [16-18,21-33,36-41,43,44], and 14 with nonaspirin NSAIDs [23,25-28,30,32,35,36, 38-41,44]. Eleven studies were concerned about advanced prostate cancer [18,24,26-28,30,37-39,41,43]. Information was collected from either databases or questionnaires. Detailed characteristics of the eligible studies are listed in Table 1.

\section{Intake of aspirin and prostate cancer}

Of the 24 studies concerned with aspirin intake, we observed that the intake of aspirin was associated with a marginally decreased risk of prostate cancer ( $\mathrm{OR}=0.95$, $95 \% \mathrm{CI}=0.93$ to 0.98 ) (Figure 2). A statistical heterogeneity was detected, therefore, random-effect analysis was performed $\left(I^{2}=60.7 \%, P<0.001\right)$. The risk of advanced prostate cancer was lower than that of prostate cancer (OR $=0.89,95 \% \mathrm{CI}=0.82$ to 0.96$)$. The fixed-effect analysis was conducted and no significant heterogeneity was found $\left(I^{2}=4.5 \%, P=0.4\right)$.

Begg's and Egger's tests were performed to evaluate publication bias among the included studies; no such bias was found by either Begg's or Egger's test $(P=0.503$, $P=0.160$, respectively).

For stratified analysis, the summarized OR estimates indicated that the intake of aspirin was associated with a decreased risk of prostate cancer in the USA (OR $=0.937$, $95 \% \mathrm{CI}=0.900$ to 0.975 ). However, no such association was detected in other countries (OR $=0.969$, $95 \% \mathrm{CI}=0.934$ to 1.006 ). When subgroup analysis was performed by study design, we observed a marginally protective effect of aspirin on prostate cancer in the cohort group ( $\mathrm{OR}=0.930,95 \% \mathrm{CI}=0.894$ to 0.967$)$. Nevertheless, no such effect was found in the case-control group
(OR $=0.976,95 \% \mathrm{CI}=0.940$ to 1.013$)$. Detailed data are given in Table 2.

\section{All-NSAID intake and prostate cancer}

A total of 11 studies were associated with all-NSAID intake and prostate cancer. Compared with previous meta-analyses, we observed a positive relationship between all-NSAID intake and prostate cancer risk, owing to new research $(\mathrm{OR}=1.18,95 \% \mathrm{CI}=1.15$ to 1.22$)$. A random-effect analysis was conducted, owing to significantly statistical heterogeneity $\left(I^{2}=92.4 \%, P<0.001\right)$. Similar results were found between all-NSAID intake and advanced prostate cancer (OR $=1.43,95 \% \mathrm{CI}=1.32$ to $\left.1.56, I^{2}=92.8 \%, P<0.001\right)$. No publication bias was detected when Begg's and Egger's tests were conducted ( $P=0.312, P=0.190$, respectively).

In the subgroup analysis, the pooled OR estimates suggested that no direct relationship between allNSAID intake and prostate cancer risk was observed in the USA ( $\mathrm{OR}=0.922,95 \% \mathrm{CI}=0.836$ to 1.016$)$. Notably, we detected a positive correlation between all-NSAID intake and prostate cancer risk (OR $=1.212,95 \% \mathrm{CI}=1.174$ to 1.251). When stratified analysis was conducted by study design, we did not observe a protective effect on prostate cancer in the cohort group ( $\mathrm{OR}=1.022,95 \% \mathrm{CI}=0.938$ to 1.113). However, in case-control groups, all-NSAID intake could be a potential risk factor in prostate carcinogenesis ( $\mathrm{OR}=1.205,95 \% \mathrm{CI}=1.167$ to 1.245$)$. Detailed data are illustrated in Table 2.

\section{Nonaspirin NSAID intake and prostate cancer}

Among the 14 articles related to nonaspirin NSAIDs and prostate cancer risk, we observed a marginally inverse relation ( $\mathrm{OR}=0.94,95 \% \mathrm{CI}=0.90$ to 0.98 ) (Figure 3 ). A significantly statistical heterogeneity was observed, thus random-effect analysis was performed $\left(I^{2}=55.9 \%, P<0.01\right)$. Nevertheless, an opposite relation was detected between nonaspirin NSAID intake and advanced prostate cancer $\left(\mathrm{OR}=1.25,95 \% \mathrm{CI}=1.13\right.$ to $\left.1.38, I^{2}=65.8 \%, P<0.01\right)$.

Begg's and Egger's tests were conducted to assess for publication bias among the included articles; no such bias was detected by either Begg's or Egger's test $(P=0.956$, $P=0.500$, respectively).

In the stratified analysis, the summarized OR estimates showed that nonaspirin NSAIDs were associated with a decreased risk of prostate cancer in other countries except the USA (OR $=0.915,95 \% \mathrm{CI}=0.869$ to 0.964 ). However, we failed to find a similar relation in the USA (OR $=1.009,95 \% \mathrm{CI}=0.927$ to 1.099$)$. When stratified analysis was performed on study design, we observed a marginally protective effect on prostate cancer in the case-control group ( $\mathrm{OR}=0.922,95 \% \mathrm{CI}=0.876$ to 0.971 ). Nevertheless, no such result was detected in the cohort 
Table 1 Characteristics of the included studies on nonsteroidal anti-inflammatory drugs intake and prostate cancer

\begin{tabular}{|c|c|c|c|c|c|c|}
\hline First author & Published year & Study design & Country & Drugs & Study period & Information resource \\
\hline Paganini-Hill [16] & 1989 & Cohort & USA & Aspirin & 1981 to 1988 & Questionnaire \\
\hline Schreinemachers [22] & 1994 & Cohort & USA & Aspirin & 1971 to 1987 & Questionnaire \\
\hline Neugut [31] & 1998 & Case-control & USA & Aspirin & 1984 to 1986 & Questionnaire \\
\hline Norrish [38] & 1998 & Case-control & New Zealand & Aspirin, NA-NSAIDs, NSAIDs & 1996 & Questionnaire \\
\hline Nelson [25] & 2000 & Case-control & USA & Aspirin, NA-NSAIDs & 1992 to 1995 & Questionnaire \\
\hline Langman [34] & 2000 & Case-control & UK & NSAIDs & 1993 to 1995 & Database \\
\hline Leitzmann [18] & 2002 & Cohort & USA & Aspirin & 1986 to 1998 & Questionnaire \\
\hline Roberts [20] & 2002 & Cohort & USA & NSAIDs & 1990 to 1996 & Questionnaire \\
\hline Habel [24] & 2002 & Cohort & USA & Aspirin & 1964 to 1996 & Questionnaire \\
\hline Irani [35] & 2002 & Case-control & France & NA-NSAIDs & 1999 to 2000 & Questionnaire \\
\hline Sorensen [19] & 2003 & Cohort & Denmark & NSAIDS & 1989 to 1995 & Database \\
\hline Friis [29] & 2003 & Cohort & Denmark & Aspirin & 1989 to 1997 & Database \\
\hline Perron [33] & 2003 & Cohort & Canada & Aspirin, NSAIDs & 1993 to 1996 & Database \\
\hline Ratnasinghe [17] & 2004 & Cohort & USA & Aspirin & 1976 to 1992 & Questionnaire \\
\hline García Rodríguez [36] & 2004 & Cohort & UK & Aspirin, NA-NSAIDs & 1995 to 2001 & Database \\
\hline Jacobs [28] & 2005 & Cohort & USA & Aspirin, NA-NSAIDs, NSAIDs & 1992 to 2001 & Questionnaire \\
\hline Platz [40] & 2005 & Cohort & USA & Aspirin, NA-NSAIDs & 1980 to 2004 & Questionnaire \\
\hline Bosetti [21] & 2006 & Case-control & Italy & Aspirin & 1991 to 2002 & Questionnaire \\
\hline Dasgupta [23] & 2006 & Case-control & Canada & Aspirin, NA-NSAIDs & 1999 to 2002 & Database \\
\hline Mahmud [26] & 2006 & Case-control & Canada & Aspirin, NA-NSAIDs, NSAIDs & 1999 to 2003 & Questionnaire \\
\hline Menezes [41] & 2006 & Case-control & USA & Aspirin, NA-NSAIDs & 1982 to 1998 & Questionnaire \\
\hline Murad [32] & 2010 & Case-control & UK & Aspirin, NA-NSAIDs, NSAIDs & 2001 to 2008 & Database \\
\hline Brasky [39] & 2010 & Cohort & USA & Aspirin, NA-NSAIDs & 2000 to 2007 & Questionnaire \\
\hline Coogan [42] & 2010 & Case-control & USA & NSAIDS & 1992 to 2008 & Questionnaire \\
\hline Salinas [43] & 2010 & Case-control & USA & Aspirin & 2002 to 2005 & Questionnaire \\
\hline Dhillon [37] & 2011 & Cohort & USA & Aspirin & 1988 to 2006 & Questionnaire \\
\hline Mahmud [44] & 2011 & Case-control & Canada & Aspirin, NA-NSAIDs, NSAIDs & 1985 to 2000 & Questionnaire \\
\hline Shebl [30] & 2012 & Cohort & USA & Aspirin, NA-NSAIDs & 1993 to 2009 & Questionnaire \\
\hline Veitonmaki [27] & 2013 & Case-control & Finland & Aspirin, NA-NSAIDs, NSAIDs & 1995 to 2002 & Database \\
\hline
\end{tabular}

NA-NSAIDs, nonaspirin nonsteroidal anti-inflammatory drugs; NSAIDs, total nonsteroidal anti-inflammatory drugs.

group $(\mathrm{OR}=0.992,95 \% \mathrm{CI}=0.909$ to 1.083$)$. Detailed data are illustrated in Table 2.

\section{Sensitivity analysis}

Simultaneously, sensitivity analyses were conducted to evaluate the effect of each study on the overall estimate by sequentially excluding each study in turn. In our meta-analysis, we found that probably no study could affect the summary of risk estimate (data not shown).

\section{Discussion}

Nonsteroidal anti-inflammatory drugs are one of the most commonly used medicine types in the whole world. Studies showed that daily nonsteroidal anti-inflammatory drug intake could be a non-invasive, economical, and valuable method of preventing cancer. Previous research illustrated that inflammation was involved in the process of prostate carcinogenesis [45]. Evidence demonstrated that cyclooxygenase enzymes, the targets of most NSAIDs, played a critical role in the development of prostate cancer [8]. Further studies verified that NSAIDs could inhibit the development and progression of prostate cancer, which meant that NSAIDs might be effective in the prevention of prostate cancer [9]. Nevertheless, conflicting results were obtained by different research centers. Therefore, we performed a meta-analysis to evaluate both the strength and consistency of the potential association between NSAID intake and prostate cancer risk.

We observed that the intake of aspirin was associated with a marginally decreased risk of prostate cancer ( $\mathrm{OR}=0.95,95 \% \mathrm{CI}=0.93$ to 0.98$)$. The risk of advanced prostate cancer was less than that of prostate cancer 


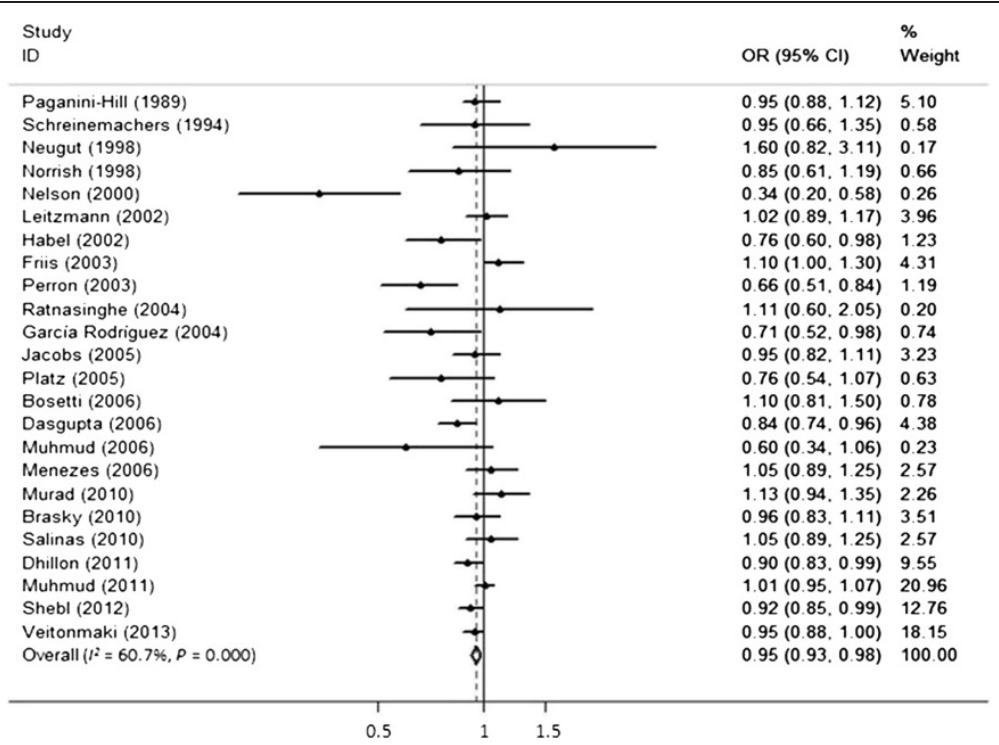

Figure 2 Forest plots depicting the risk estimates from included studies on the association between the intake of aspirin and prostate cancer risk. $\mathrm{Cl}$, confidence interval; OR, odds ratio.

( $\mathrm{OR}=0.89,95 \% \mathrm{CI}=0.82$ to 0.96$)$. This indicated that the intake of aspirin showed a marginally inverse correlation with prostate cancer risk. The results of the 24 studies included in our analysis were heterogeneous, probably resulting from differences in country and study design. To further illustrate the relationship between the intake of aspirin and prostate cancer risk, subgroup analyses were conducted. The summarized OR estimates illustrated that the intake of aspirin was associated with a decreased risk of prostate cancer while separately analyzed by country and design of study. In the stratified analysis by country, we found that an inversed correlation between the intake of aspirin and prostate cancer risk in the USA ( $\mathrm{OR}=0.937,95 \% \mathrm{CI}=0.900$ to 0.975 ). Conversely, no such association was observed in other countries $(\mathrm{OR}=0.969$, $95 \% \mathrm{CI}=0.934$ to 1.006 ). Additionally, we found that none of the studies analyzing the association between the intake of aspirin and prostate cancer risk was conducted in Asian countries, probably because of different daily habits in those countries; this aspect requires further research.

Table 2 Stratified pooled odds ratios and $95 \%$ confidence intervals of NSAIDs intake and prostate cancer

\begin{tabular}{|c|c|c|c|c|}
\hline \multirow[t]{2}{*}{ Subgroup } & \multirow[t]{2}{*}{ Number of studies } & \multirow[t]{2}{*}{ Odds ratio ( $95 \%$ confidence interval) } & \multicolumn{2}{|c|}{ Heterogeneity } \\
\hline & & & $P$ & $I^{2}(\%)$ \\
\hline \multicolumn{5}{|l|}{ Aspirin } \\
\hline USA & 14 & $0.937(0.900,0.975)$ & 0.012 & 52.0 \\
\hline Other countries & 10 & $0.969(0.934,1.006)$ & 0.000 & 70.0 \\
\hline Cohort studies & 13 & $0.930(0.894,0.967)$ & 0.025 & 48.6 \\
\hline Case-control studies & 11 & $0.976(0.940,1.013)$ & 0.000 & 69.0 \\
\hline \multicolumn{5}{|l|}{ NSAIDs } \\
\hline USA & 3 & $0.922(0.836,1.016)$ & 0.011 & 77.7 \\
\hline Other countries & 8 & $1.212(1.174,1.251)$ & 0.000 & 92.7 \\
\hline Cohort studies & 4 & $1.022(0.938,1.113)$ & 0.000 & 90.2 \\
\hline Case-control studies & 7 & $1.205(1.167,1.245)$ & 0.000 & 93.3 \\
\hline \multicolumn{5}{|l|}{ NA-NSAIDs } \\
\hline USA & 6 & $1.009(0.927,1.099)$ & 0.807 & 0.0 \\
\hline Other countries & 8 & $0.915(0.869,0.964)$ & 0.001 & 70.3 \\
\hline Cohort studies & 5 & $0.992(0.909,1.083)$ & 0.629 & 0.0 \\
\hline Case-control studies & 9 & $0.922(0.876,0.971)$ & 0.002 & 67.9 \\
\hline
\end{tabular}




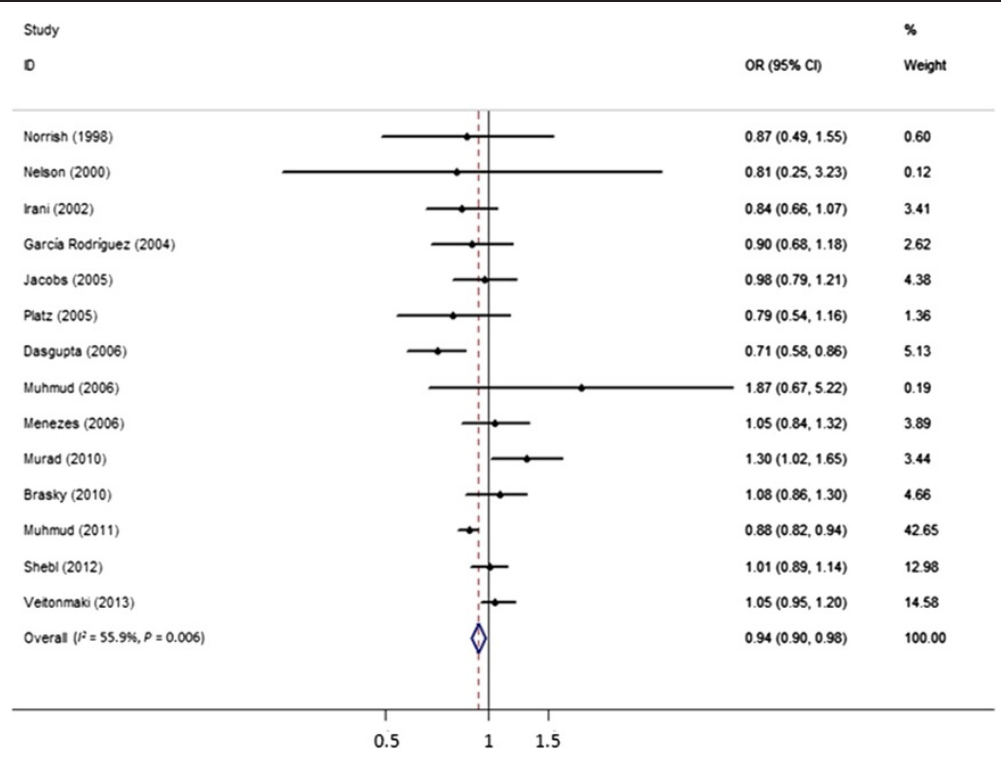

Figure 3 Forest plots depicting the risk estimates from included studies on the association between nonaspirin NSAID intake and prostate cancer risk. $\mathrm{Cl}$, confidence interval; OR, odds ratio.

A total of 11 studies were associated with all-NSAID intake and prostate cancer risk. We found a positive relation between all-NSAID intake and prostate cancer risk, owing to more recent research, compared with previous meta-analyses ( $\mathrm{OR}=1.18,95 \% \mathrm{CI}=1.15$ to 1.22 ). Similar results were found between all-NSAID intake and advanced prostate cancer $(\mathrm{OR}=1.43,95 \% \mathrm{CI}=1.32$ to 1.56). To explain the phenomenon, we took a deeper look at the included studies. One study conducted in Finland illustrated a significantly elevated prostate cancer risk of total and advanced prostate cancer among allNSAID users [27]. The association was not dose-dependent in the study, indicating that it could result from systematic differences between users of prescription NSAIDs and users of non-prescription NSAIDs. Furthermore, people who take prescribed NSAIDs are possibly frequent users of other health services, such as cancer screening, including testing for prostate-specific antigen. This could bring about a positive detection bias.

Meanwhile, among the 14 articles associated with nonaspirin NSAIDs and prostate cancer risk, we observed a marginally inverse correlation between them $(\mathrm{OR}=0.94$, $95 \% \mathrm{CI}=0.90$ to 0.98$)$. Nevertheless, an opposite correlation was detected between nonaspirin NSAIDs intake and advanced prostate cancer $(\mathrm{OR}=1.25,95 \% \mathrm{CI}=1.13$ to 1.38$)$.

\section{Our study could have limitations in several ways}

Firstly, although no publication bias was detected in our analysis, using both Begg's and Egger's tests, the strategy of selection of published studies in English only and the exclusion of studies without sufficient information could bring about possible publication bias, which remains an alternative explanation of our results. Furthermore, our search was restricted to published articles, which could also cause potential bias to affect our findings.

Secondly, both case-control and cohort studies with different populations, drug intakes, and outcomes were included in our analysis. Considering the existing heterogeneity, it could be inappropriate to choose a single global effect estimate to pool the data, and the summarized estimates in our study should be treated with caution [46]. Therefore, we performed stratified analyses to explain the possible sources of heterogeneity [47]. Additionally, some studies were case-control ones; these could lead to selection and recall bias.

Thirdly, there are several types of NSAID, which could have different effects on prostate cancer. However, most studies recruited in our study merely provided general data on NSAID intake rather than detailed information on specific dose and duration of use, which might bring about inaccurate estimates.

\section{Conclusions}

We conducted a detailed meta-analysis for summarized OR estimates from researches focused on the association between NSAIDs intake and prostate cancer risk. Although we could not deny possible confounding factors, the results indicated a marginally inverse correlation between the intake of aspirin and prostate cancer risk. On the contrary, a positive relation between all-NSAID intake and prostate cancer was observed. Further research needs to be conducted to better clarify potential biological mechanisms. 


\section{Abbreviations}

Cl: confidence interval; NSAID: nonsteroidal anti-inflammatory drug; OR: odds ratio.

\section{Competing interests}

The authors declare that they had no competing interest.

\section{Authors' contributions}

$X W$ and $Y W L$ drafted the manuscript. JW, $Y Z$, and $X Y Z$ assisted with manuscript preparation. $X L X, Z H H$, and $X X$ extracted the data from the articles. $Z \mathrm{~L}, \mathrm{SQL}$, and $\mathrm{LPX}$ revised the manuscript. All authors have read and approved the final manuscript.

\section{Acknowledgements}

The work was supported by grants from the National Key Clinical Specialty Construction Project of China, key medical disciplines of Zhejiang province, Combination of traditional Chinese and Western medicine key disciplines of Zhejiang province (2012-XK-A23), and a health sector scientific research special project (201002010).

Received: 28 May 2014 Accepted: 25 September 2014 Published: 5 October 2014

\section{References}

1. Siegel R, Naishadham D, Jemal A: Cancer statistics, 2013. CA Cancer J Clin 2013, 63(1):11-30.

2. Belpomme $D$, Irigaray $\mathrm{P}$, Ossondo M, Vacque D, Martin M: Prostate cancer as an environmental disease: an ecological study in the French Caribbean islands, Martinique and Guadeloupe. Int J Oncol 2009, 34(4):1037-1044

3. Wang $X$, Wang S, Lin YW, Wu J, Chen H, Mao YQ, Zheng XY, Zhou C, Xie LP: Angiotensin-converting enzyme insertion/deletion polymorphism and the risk of prostate cancer in the Han population of China. Med Oncol 2012, 29(3):1964-1971.

4. Quinn M, Babb P: Patterns and trends in prostate cancer incidence, survival, prevalence and mortality. Part I: international comparisons. BJU Int 2002, 90(2):162-173.

5. Rostom A, Dube C, Lewin G, Tsertsvadze A, Barrowman N, Code C, Sampson M, Moher D: NSAIDs and cyclooxygenase-2 inhibitors for primary prevention of colorectal cancer: a systematic review prepared for the U.S. Preventive Services Task Force. Ann Intern Med 2007, 146(5):376-389.

6. Corley DA, Kerlikowske K, Verma R, Buffler P: Protective association of aspirin/NSAIDs and esophageal cancer: a systematic review and meta-analysis. Gastroenterology 2003, 124(1):47-56.

7. Khuder SA, Mutgi AB: Breast cancer and NSAID use: a meta-analysis. Br J Cancer 2001, 84(9):1188-1192.

8. Vane JR, Bakhle YS, Botting RM: Cyclooxygenases 1 and 2. Annu Rev Pharmacol Toxicol 1998, 38:97-120.

9. Sabichi AL, Lippman SM: COX-2 inhibitors and other NSAIDs in genitourinary cancer. Semin Oncol 2004, 31(2 Suppl 7):36-44.

10. Mahmud SM, Franco EL, Aprikian AG: Use of NSAIDs and prostate cancer risk: a meta-analysis. Int J Cancer 2010, 127(7):1680-1691.

11. Mantel N, Haenszel W: Statistical aspects of the analysis of data from retrospective studies of disease. J Nat Cancer Inst 1959, 22(4):719-748.

12. DerSimonian R, Laird N: Meta-analysis in clinical trials. Control Clin Trials 1986, 7(3):177-188

13. Higgins JP, Thompson SG, Deeks JJ, Altman DG: Measuring inconsistency in meta-analyses. BMJ 2003, 327(7414):557-560.

14. Egger M, Davey Smith G, Schneider M, Minder C: Bias in meta-analysis detected by a simple, graphical test. BMJ 1997, 315(7109):629-634

15. Begg CB, Mazumdar M: Operating characteristics of a rank correlation test for publication bias. Biometrics 1994, 50(4):1088-1101.

16. Paganini-Hill A, Chao A, Ross RK, Henderson BE: Aspirin use and chronic diseases: a cohort study of the elderly. BMJ 1989, 299(6710):1247-1250

17. Ratnasinghe LD, Graubard BI, Kahle L, Tangrea JA, Taylor PR, Hawk E: Aspirin use and mortality from cancer in a prospective cohort study. Anticancer Res 2004, 24(5B):3177-3184.

18. Leitzmann MF, Stampfer MJ, Ma J, Chan JM, Colditz GA, Willett WC, Giovannucci E: Aspirin use in relation to risk of prostate cancer. Cancer Epidemiol Biomarkers Prev 2002, 11(10 Pt 1):1108-1111.
19. Sorensen HT, Friis S, Norgard B, Mellemkjaer L, Blot WJ, McLaughlin JK, Ekbom A, Baron JA: Risk of cancer in a large cohort of nonaspirin NSAID users: a population-based study. Br J Cancer 2003, 88(11):1687-1692.

20. Roberts RO, Jacobson DJ, Girman CJ, Rhodes T, Lieber MM, Jacobsen SJ: A population-based study of daily nonsteroidal anti-inflammatory drug use and prostate cancer. Mayo Clin Proc 2002, 77(3):219-225.

21. Bosetti C, Talamini R, Negri E, Franceschi S, Montella M, La Vecchia C: Aspirin and the risk of prostate cancer. Eur J Cancer Prev 2006, 15(1):43-45

22. Schreinemachers DM, Everson RB: Aspirin use and lung, colon, and breast cancer incidence in a prospective study. Epidemiology 1994, 5(2):138-146.

23. Dasgupta K, Di Cesar D, Ghosn J, Rajan R, Mahmud S, Rahme E: Association between NSAIDs and prostate cancer occurrence. Cancer J 2006, 12(2):130-135.

24. Habel LA, Zhao W, Stanford JL: Daily aspirin use and prostate cancer risk in a large, multiracial cohort in the US. Cancer Causes Control 2002, 13(5):427-434

25. Nelson JE, Harris RE: Inverse association of prostate cancer and non-steroidal anti-inflammatory drugs (NSAIDs): results of a case-control study. Oncol Rep 2000, 7(1):169-170

26. Mahmud SM, Tanguay S, Begin LR, Franco EL, Aprikian AG: Non-steroida anti-inflammatory drug use and prostate cancer in a high-risk population. Eur J Cancer Prev 2006, 15(2):158-164.

27. Veitonmaki T, Tammela TL, Auvinen A, Murtola TJ: Use of aspirin, but not other non-steroidal anti-inflammatory drugs is associated with decreased prostate cancer risk at the population level. Eur J Cancer 2013, 49(4):938-945.

28. Jacobs EJ, Rodriguez C, Mondul AM, Connell CJ, Henley SJ, Calle EE, Thun MJ: A large cohort study of aspirin and other NSAIDs and prostate cancer incidence. J Natl Cancer Inst 2005, 97(13):975-980.

29. Friis S, Sorensen HT, MCLaughlin JK, Johnsen SP, Blot WJ, Olsen JH: A population-based cohort study of the risk of colorectal and other cancers among users of low-dose aspirin. Br J Cancer 2003, 88(5):684-688.

30. Shebl FM, Sakoda LC, Black A, Koshiol J, Andriole GL, Grubb R, Church TR, Chia D, Zhou C, Chu LW, Huang WY, Peters U, Kirsh VA, Chatterjee N, Leitzmann MF, Hayes RB, Hsing AW: Aspirin but not ibuprofen use is associated with reduced risk of prostate cancer: a PLCO study. $\mathrm{Br} J$ Cancer 2012, 107(1):207-214.

31. Neugut Al, Rosenberg DJ, Ahsan H, Jacobson JS, Wahid N, Hagan M, Rahman MI, Khan ZR, Chen L, Pablos-Mendez A, Shea S: Association between coronary heart disease and cancers of the breast, prostate, and colon. Cancer Epidemiol Biomarkers Prev 1998, 7(10):869-873.

32. Murad AS, Smith GD, Lewis SJ, Cox A, Donovan JL, Neal DE, Hamdy FC, Martin RM: A polymorphism in the glucokinase gene that raises plasma fasting glucose, rs1799884, is associated with diabetes mellitus and prostate cancer: findings from a population-based, case-control study (the ProtecT study). Int J Mol Epidemiol Genet 2010, 1(3):175-183.

33. Perron L, Bairati I, Moore L, Meyer F: Dosage, duration and timing of nonsteroidal antiinflammatory drug use and risk of prostate cancer. Int J Cancer 2003, 106(3):409-415.

34. Langman MJ, Cheng KK, Gilman EA, Lancashire RJ: Effect of anti-inflammatory drugs on overall risk of common cancer: case-control study in general practice research database. BMJ 2000, 320(7250):1642-1646.

35. Irani J, Ravery V, Pariente JL, Chartier-Kastler E, Lechevallier E, Soulie M, Chautard D, Coloby P, Fontaine E, Bladou F, Desgrandchamps F, Haillot O: Effect of nonsteroidal anti-inflammatory agents and finasteride on prostate cancer risk. J Urol 2002, 168(5):1985-1988.

36. García Rodríguez LA, González-Pérez A: Inverse association between nonsteroidal anti-inflammatory drugs and prostate cancer. Cancer Epidemiol Biomarkers Prev 2004, 13(4):649-653.

37. Dhillon PK, Kenfield SA, Stampfer MJ, Giovannucci EL: Long-term aspirin use and the risk of total, high-grade, regionally advanced and lethal prostate cancer in a prospective cohort of health professionals, 1988-2006. Int J Cancer 2011, 128(10):2444-2452.

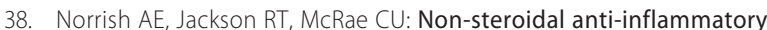
drugs and prostate cancer progression. Int J Cancer 1998, 77(4):511-515.

39. Brasky TM, Velicer CM, Kristal AR, Peters U, Potter JD, White E: NSAIDs and prostate cancer risk in the VITamins And Lifestyle (VITAL) cohort. Cance Epidemiol Biomarkers Prev 2010, 19(12):3185-3188. 
40. Platz EA, Rohrmann S, Pearson JD, Corrada MM, Watson DJ, De Marzo AM, Landis PK, Metter EJ, Carter HB: NSAIDs and risk of prostate cancer in the Baltimore Longitudinal Study of Aging. Cancer Epidemiol Biomarkers Prev 2005, 14(2):390-396.

41. Menezes RJ, Swede H, Niles R, Moysich KB: Regular use of aspirin and prostate cancer risk (United States). Cancer Causes Control 2006, 17(3):251-256.

42. Coogan PF, Kelly JP, Strom BL, Rosenberg L: Statin and NSAID use and prostate cancer risk. Pharmacoepidemiol Drug Saf 2010, 19(7):752-755.

43. Salinas CA, Kwon EM, FitzGerald LM, Feng Z, Nelson PS, Ostrander EA, Peters $U$, Stanford JL: Use of aspirin and other nonsteroidal antiinflammatory medications in relation to prostate cancer risk. Am J Epidemiol 2010, 172(5):578-590.

44. Mahmud SM, Franco EL, Turner D, Platt RW, Beck P, Skarsgard D, Tonita J, Sharpe C, Aprikian AG: Use of non-steroidal anti-inflammatory drugs and prostate cancer risk: a population-based nested case-control study. PLOS One 2011, 6(1):e16412.

45. Lieberman R: Chemoprevention of prostate cancer: current status and future directions. Cancer Metastasis Rev 2002, 21(3-4):297-309.

46. Egger M, Smith GD, Phillips AN: Meta-analysis: principles and procedures. BMJ 1997, 315(7121):1533-1537.

47. Stroup DF, Berlin JA, Morton SC, Olkin I, Williamson GD, Rennie D, Moher D, Becker BJ, Sipe TA, Thacker SB: Meta-analysis of observational studies in epidemiology: a proposal for reporting. Meta-analysis Of Observational Studies in Epidemiology (MOOSE) group. JAMA 2000, 283(15):2008-2012.

doi:10.1186/1477-7819-12-304

Cite this article as: Wang et al:: Meta-analysis of nonsteroidal anti-inflammatory drug intake and prostate cancer risk. World Journal of Surgical Oncology 2014 12:304.

\section{Submit your next manuscript to BioMed Central and take full advantage of:}

- Convenient online submission

- Thorough peer review

- No space constraints or color figure charges

- Immediate publication on acceptance

- Inclusion in PubMed, CAS, Scopus and Google Scholar

- Research which is freely available for redistribution 